\title{
Full Mouth Rehabilitation of a Child with Cerebral Palsy under General Anesthesia
}

\author{
${ }^{1}$ AR Jaya, ${ }^{2} \mathrm{P}$ Praveen, ${ }^{3} \mathrm{~A}$ Ananthraj, ${ }^{4}$ Nidhi K Nihal
}

\begin{abstract}
Cerebral palsy is defined as a nonprogressive brain disorder of movement and posture. The patient is characterized by mental and motor disabilities, sensory impairments of vision and hearing, besides having seizures and contraction joints. The dentist, doctors and healthcare professionals who treat patients with disabilities play an important role in health promotion and improvement in quality of life through multidisciplinary clinical planning especially in cerebral palsy patients who need special care. The aim of this case report was to describe a clinical case in which preventive and surgical interventions were performed in a 6-year-old male child with cerebral palsy under general anesthesia who reported to the Department of Pediatric and Preventive Dentistry, DAPMRV Dental College, Bengaluru, with the chief complaint of pain and swelling in upper left and lower right back tooth region. The approach targeted to the oral health of the patient with cerebral palsy can be considered as an important strategy for promoting the overall health and quality of life.
\end{abstract}

Keywords: Cerebral palsy, Full mouth rehabilitation, General anesthesia.

How to cite this article: Jaya AR, Praveen P, Ananthraj A, Nihal NK. Full Mouth Rehabilitation of a Child with Cerebral Palsy under General Anesthesia. J Health Sci Res 2014;5(2):29-32.

Source of support: Nil

Conflict of interest: None

\section{INTRODUCTION}

Cerebral palsy is a term used to describe a group of disorders of movement, muscle tone, or other features that reflect abnormal control over motor function by the central nervous system. ${ }^{1}$ According to the Swedish

\footnotetext{
${ }^{1}$ Senior Lecturer, ${ }^{2}$ Professor, ${ }^{3}$ Professor and Head

${ }^{4}$ Private Practitioner

${ }^{1}$ Department of Pediatric and Preventive Dentistry, Rajarajeswari Dental College and Hospital, Bengaluru, Karnataka India

${ }^{2,3}$ Department of Pediatric and Preventive Dentistry, DAPMRV Dental College, Bengaluru, Karnataka, India

${ }^{4}$ Department of Pedodontics, Kolkata, West Bengal, India
}

Corresponding Author: AR Jaya, Senior Lecturer, Department of Pediatric and Preventive Dentistry, Rajarajeswari Dental College and Hospital, Ramohalli Cross, Kumbalgodu, Mysore Road, Bengaluru, Karnataka, India, Phone: 09880038038 e-mail: jaya.vrushabh@gmail.com classification system, cerebral palsy can be classified as spastic, dyskinetic, ataxic and mixed type. ${ }^{2}$

The frequency of occurrence of oral diseases such as caries, periodontal diseases, malocclusion, bruxism and enamel hypoplasia is more compared to the general population due to a number of factors such as poor oral hygiene, type and consistency of food, use of medications, tonicity of facial muscles, lack of information by the persons responsible for the patient and the lack of access to specialized dental services. ${ }^{3}$ Hence, there is a need to adopt special, intensive and above all, individual care of patients with cerebral palsy, particularly during preventive and minimal dental interventions.

Here we present a case of cerebral palsy in a child with multiple carious teeth, in whom full mouth rehabilitation was carried out under general anesthesia.

\section{CASE REPORT}

A male patient aged 6 years, a known case of cerebral palsy of spastic type reported to the Department of Pediatric and Preventive Dentistry, DAPMRV Dental College with the chief complaint of pain in the upper left and lower right back tooth region since 15 days and fever since 2 days. The pain was severe and lancinating type, aggravated during night and subsided on taking medication prescribed by the child's physician. The child visited the dentist for the first time. Patient presented with low IQ and showed minimal response to verbal commands. The child had difficulties with speech. Radiographs could not be taken due to lack of coordination of intraoral, perioral and masticatory musculature. The child was undergoing physiotherapy for improving the muscle coordination and was on clonazepam to control convulsions. Diet history revealed that patient preferred soft and pasty dishes and he liked sweet dishes more. He did not allow the mother to carry out oral hygiene practices due to pain since 15 days and the teeth were cleaned by just wiping with a wet cloth.

The intraoral clinical soft tissue examination showed gingival inflammation in relation to upper and lower posterior teeth due to food and plaque accumulation. Inference of oral hygiene index-simplified was moderate. Intraoral hard-tissue examination showed dental caries in relation to $51,61,55,65$ and 85 , deep dental caries in 
relation to $64,74,75$, periapical abscess in relation to 84 with pathologic mobility where intraoral gingival swelling measuring about $1 \mathrm{~mm}$ was seen at the apex of 84 , and root stumps in relation to 54 (Figs 1 and 2). There was generalized attrition noticed due to bruxism.

The complete treatment plan for full mouth rehabilitation that includes stabilization of caries, pulp therapy, and extraction was discussed with parents. As the child was not able to follow the verbal commands treating the child under general anesthesia (GA) was discussed. The parents were also convinced and gave the consent to carry out the dental procedure under GA.

Pediatrician's consent on medical health of patient was obtained and after all the necessary blood investigations the child was admitted to carry out the procedure. Under GA, pulpectomy followed by stainless steel crown was done in relation to 64,74 and 75 . Since the child had a

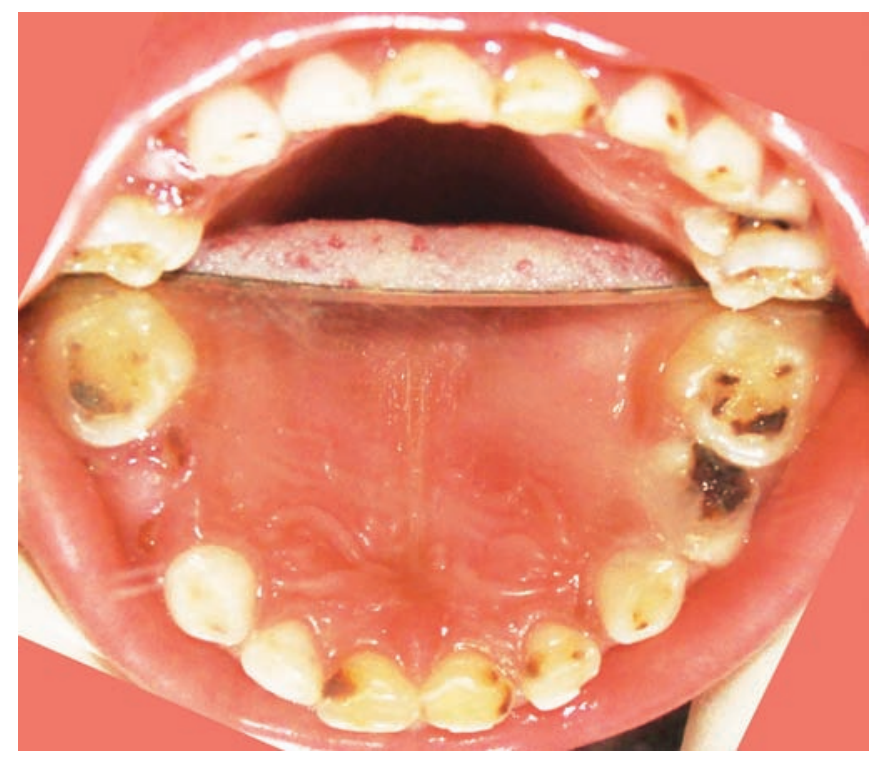

Fig. 1: Preoperative photograph—maxillary arch

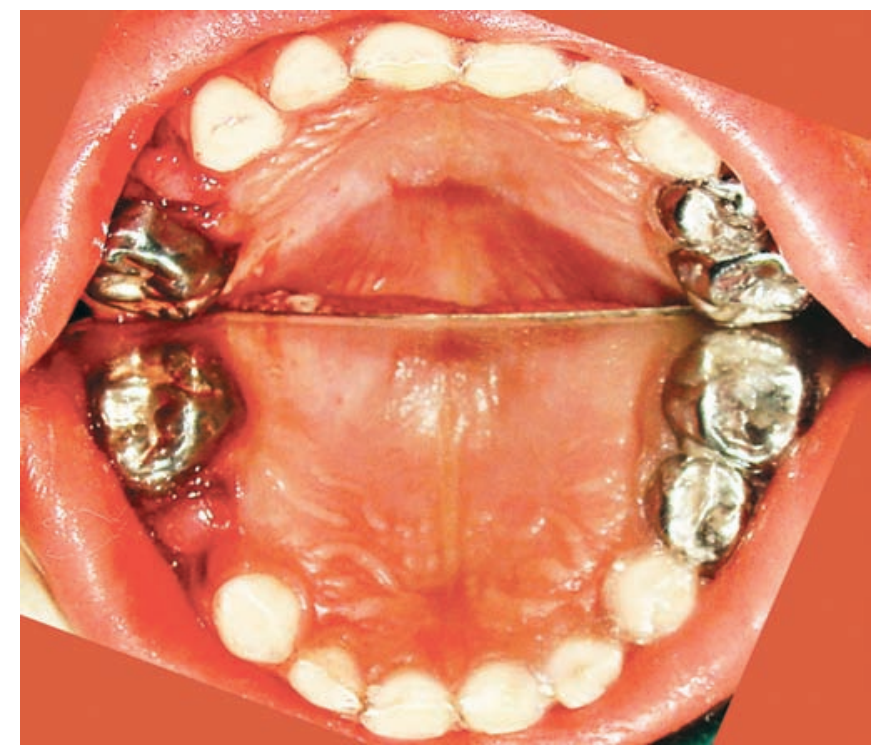

Fig. 3: Postoperative photograph—maxillary arch history of bruxism, caries was excavated and intentional stainless steel crown done in relation to 55, 65 and 85 . Glass ionomer cement restoration was done in relation to 51 and 61. Extraction of 54 and 84 was done as they were nonrestorable (Figs 3 and 4). The treatment was completed in one visit.

The patient was recalled after a week for review and it was observed that the pain and swelling had subsided and the extraction site had healed uneventfully. The patient was periodically followed up during the subsequent visit. The parents were satisfied as the food intake by the child had increased and buxism had reduced drastically.

\section{DISCUSSION}

Cerebral palsy is one of the primary handicapping conditions of childhood and is defined as a group of movement and posture disorders, caused by a lesion

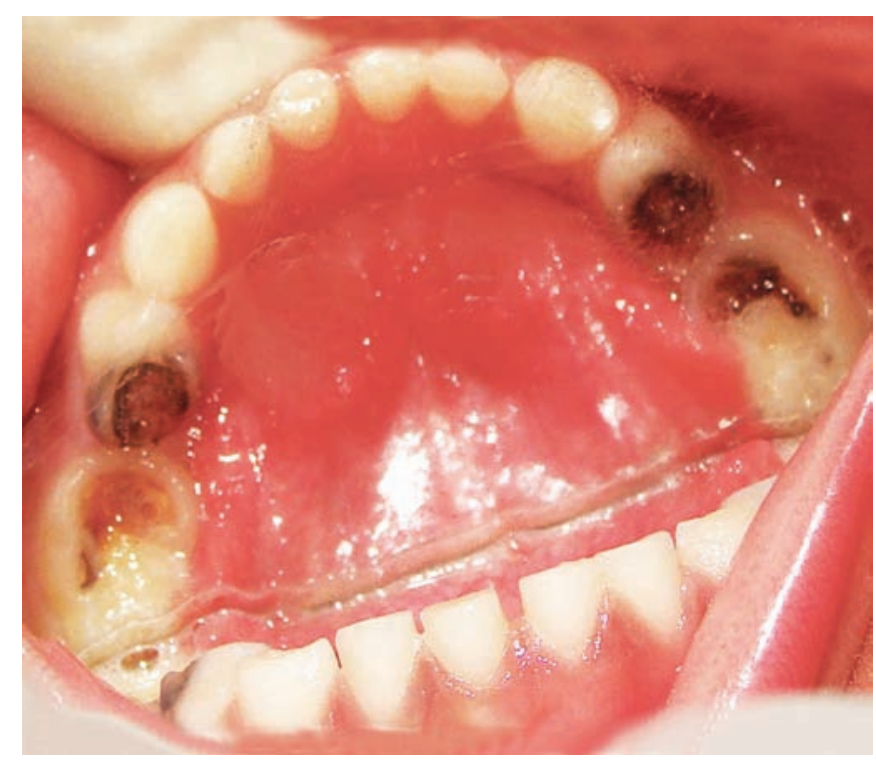

Fig. 2: Preoperative photograph—mandibular arch

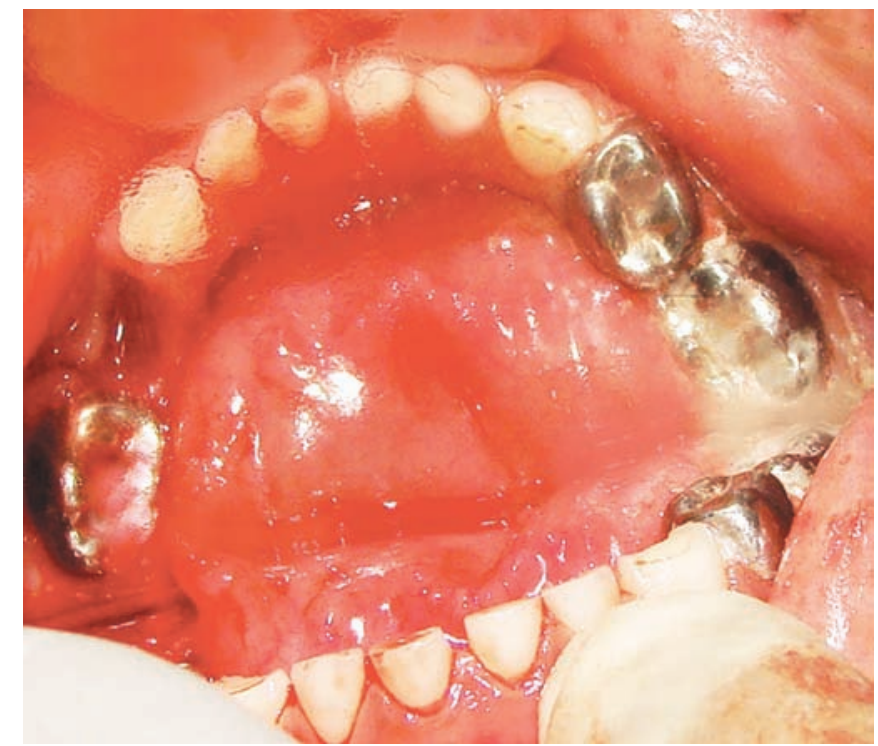

Fig. 4: Postoperative photograph-mandibular arch 
that occurred in the developing fetal or infant brain. ${ }^{4}$ Its global prevalence is 2.1 per 1000 live births. ${ }^{5}$ This disability might involve alterations in sensation, cognition, communication and behavior causing difficulty in performing daily activities like feeding, mobility and maintenance of general and oral hygiene and, hence, justifying the need to adopt special, intensive and above all, individual care of patients with cerebral palsy, especially during preventive and minimal dental interventions. ${ }^{3,6}$

The individuals with cerebral palsy shows high prevalence of oral diseases which mainly occurs due to injury to the nervous system leading to mental deficiency and orofacial motor dysfunction that may hinder daily oral hygiene practices thereby increasing the dental biofilm formation. The more serious the neurological deficiency in such people, the greater the risk of oral diseases. ${ }^{6-9}$

These patients also show a high prevalence of malocclusion due to disharmonious relationship between intraoral and perioral muscles, uncoordinated and uncontrolled movements of jaws, lips and tongue, traumatic dental injuries, bruxism, TMJ disorders due to motor incoordination, sialorrhea and poor dental hygiene, due to inability of these individuals in brushing their teeth 10 with some features reported in this case.

Managing a cerebral palsied child poses a big challenge for the pediatric dentist because of uncontrolled movements, difficulty of communication, low intelligence, poor concentration, convulsions, posture and difficulty in keeping the mouth open for long time to carry out the dental procedures which was also seen in this present case. ${ }^{10}$ Hence, rendering effective dental treatment for special children with multiple dental problems who require full mouth rehabilitation under GA is justifiable.

As in the present case the patient showed minimal response to verbal commands with apprehension and inability to cooperate on dental chair, it was decided to perform treatment under GA. The other treatment option is to use nitrous oxide $\left(\mathrm{N}_{2} \mathrm{O}\right)$ induced sedation during dental treatment mainly to reduce or eliminate anxiety, control unwanted movement, and raises the pain threshold however it has certain disadvantages that includes lack of potency, dependence on psychological reassurance, interference of the nasal hood, and mainly need for the patient to be able to breathe through the nose. ${ }^{11}$

Aided augmentative communication is a promising adjunct for the care of the child with communication impairment, and may be of particular value in pediatric dental practices where the staff are able to practice and master its use for selected child patients. This type of communication involves symbols placed on a communication board and may be used together with conventional behavior management techniques for successful delivery of dental treatment. ${ }^{12}$

Poor oral hygiene in patients with cerebral palsy is mainly attributed to the fact that these individuals/ family/caregivers have difficulty in brushing their teeth and due to difficulty in mouth opening. Thus, there is a need for guidance and training of those responsible to promote oral health. ${ }^{13}$ A randomized controlled trial conducted by Bozkurt et al found that patients with CP were found to have significant improvement in plaque levels and gingival health when their parents and caregivers used an electric toothbrush as opposed to a manual toothbrush. ${ }^{14}$ Two studies provided evidence that children with $\mathrm{CP}$ were better able to brush their own teeth when they were given toothbrushes that had been individually modified mainly the length and size of the handle. ${ }^{15,16}$

As in the present case mother was guided on practice of proper oral hygiene maintenance method to control plaque accumulation. The ideal dental attendance for the patient with cerebral palsy is early prevention, especially with the active participation of parents in the process of introducing oral hygiene care and associated with the specialized ambulatory treatment of these patients.

\section{CONCLUSION}

Oral health problems in patients with cerebral palsy may be due to parental belief of reduced importance to oral health in comparison to the overall scheme of health management. The multidisciplinary approach to execute the oral healthcare of such patients, as reported, may be considered as an important strategy in promoting health and quality of life.

\section{REFERENCES}

1. Al-Allaq T, DeBord TK, Liu H, Wang Y, Messadi DV. Oral health status of individuals with cerebral palsy at a nationally recognized rehabilitation center. Spec Care Dent 2015 Jan-Feb;35(1):15-21.

2. Hagberg B, Sanner G, Steen M. The disequilibrium syndrome in cerebral palsy: clinical aspects and treatment. Acta Paediatr Scand 1972;61(suppl 226):1-63.

3. da Matta GS, Barriviera M, de Aquino Marsiglio A, de Souza Peruchi CM, Miranda AF. Preventive and surgical intervention in patient with cerebral palsy-case report. RSBO 2013;10(3):278-283.

4. Bax M, Goldstein M, Rosebaum P, Leviton A, Paneth N, Dan B, et al. Executive committee for the definition of cerebral palsy: proposed definition and classification of cerebral palsy. Dev Med Child Neurol 2005 Apr;47(8):571-576.

5. Oskoui M, Coutinho F, Dykeman J, Jett N, Pringsheim T. An update on the prevalence of cerebral palsy: a systematic review and meta-analysis. Dev Med Child Neurol 2013 Jun;55(6):509-519.

6. Andreia MR, Cardoso LNG, Silva CRD, de SC Soares R, NG de Abreu MH, Padilha WWN, et al. Caries and periodontal 
disease in Brazilian children and adolescents with cerebral Palsy. Int J Environ Res Public Health 2015;12(1):335-353.

7. Anders PL, Davis EL. Oral health of patients with intellectual disabilities: a systematic review. Spec Care Dentist 2010 May-Jun;30(3):110-117.

8. Jain M, Mathur A, Sawla L, Ghoudhary G, Kabra K, Duraiswamy P, et al. Oral health status of mentally disabled subjects in India. J Oral Sci 2009 Sep;51(3):333-340.

9. Kumar S, Sharma J, Duraiswamy P, Kulkarni S. Determinants for oral hygiene and periodontal status among mentally disabled children and adolescents. J Ind Soc Pedod Prev Dent 2009 Jul-Sep;27(3):151-157.

10. Sehrawat N, Marwaha M, Bansal K, Chopra R. Cerebral palsy. a dental update. Int J Clin Pediatr Dent 2014;7(2):109-118.

11. Yoshida MI, Nakajima A, Uchida T, Yamaguchi M, Akasaka. Effect of nitrous oxide on dental patients with cerebral palsy-using an electromyogram from orofacial muscles as an index. J Oral Rehabil 2003;30(3):324-333.

12. Darwis WE, Messer LB. Aided augmentative communication in managing children with cerebral palsy. Pediatr Dent 2001; 23(2):136-139.

13. Mohan DU, Beena JP, Divya R. Importance of oral hygiene habits in mentally disabled children. IJCPD 2010;3(1):39-42.

14. Bozkurt FY, Fentoglu O, Yetkin Z. The comparison of various oral hygiene strategies in neuromuscularly disabled individuals. J Contemp Dent Pract 2004;5(4):23-31.

15. Soncini JA, Tsamtsouris A. Individually modified toothbrushes and improvement of oral hygiene and gingival health in cerebral palsy children. J Pedod 1989;9(6):331-344.

16. Damle SG, Bhavsar JP. Plaque removing efficacy of individually modified toothbrushes in cerebral palsy children. J Dent Child 1995;62(4):279-282. 